\title{
Análise das llhas de Calor Urbano sobre \\ Zonas Climáticas Locais com o uso de VANT \\ - Veículo Aéreo Não Tripulado - em uma cidade média
}

\author{
Analysis of the behavior of the Urban Heat Islands on Local \\ Climate Zones using drone in a medium-sized city
}

\author{
Otavio Reis Megda [a] [D], Erico Masiero [a] [D
}

[a] Universidade Federal de São Carlos (UFSCAR), Programa de Pós-graduação em Engenharia Urbana, São Carlos, SP, Brasil

Como citar: Megda, O. R., \& Masiero, E. (2021). Análise das Ilhas de Calor Urbano sobre Zonas Climáticas Locais com o uso de VANT - Veículo Aéreo Não Tripulado - em uma cidade média. urbe. Revista Brasileira de Gestão Urbana, v.13, e20200333. https://doi.org/10.1590/2175-3369.013.e20200333

\section{Resumo}

As cidades médias são definidas por possuírem entre 100 e 500 mil habitantes, não fazerem parte de regiões metropolitanas e apresentarem um relativo grau de avanço em sua economia e infraestrutura. Estes espaços urbanos são os que mais crescem no Brasil, os quais se configuram como densas áreas ocupadas, com uma alta variabilidade de ambientes e com diversificado padrão climático. Assim, propõe-se nesta pesquisa a aplicação de uma metodologia de estudo com o uso de VANTs (Veículos Aéreos Não Tripulados) em Zonas Climáticas Locais - ZCLs (Local Climates Zones - LCZs) em Franca - São Paulo, Brasil, para identificar as ocorrências das Ilhas de Calor Urbano (ICUs) em áreas com configurações morfológicas distintas e em diferentes alturas. A variação das ICUs foi correlacionada com a variação do Fator de Visão do Céu (FVC) a nível do pedestre, a 30, 60 e 75 metros de altura. Os resultados indicam a formação significativa de ICUs, não só a nível do pedestre, mas também pouco acima de 60 metros de altura, sobretudo no inverno. Os resultados indicam para a necessidade de se conhecer mais detalhadamente o comportamento das ICUs verticalmente em cidades médias.

Palavras-chave: Ilha de Calor Urbano. VANT. Zonas Climáticas Locais.

\begin{abstract}
Medium-sized cities are defined as having between 100 and 500 thousand inhabitants, not being part of metropolitan regions, and presenting a relative degree of progress in their economy and infrastructure. These urban spaces are the fastest growing in Brazil, which are configured as dense occupied areas, with a high variability of environments and with the diversified climatic pattern. Thus, it is proposed in this research the application of a study methodology with the use of UAVs (Unmanned Aerial Vehicles) in Local Climate Zones ZCLs (Local Climates Zones - LCZs) in Franca - São Paulo, Brazil, to identify to occurrences of Urban Heat Islands (ICUs) in areas with different morphological configurations and at different heights. The variation of the ICUs was correlated with the variation of the Sky Vision Factor (FVC) at the pedestrian level, at 30, 60 and 75 meters
\end{abstract}


in height. The results indicate the significant formation of ICUs, not only at the pedestrian level but also just above 60 meters in height, especially in winter. The fact indicates the need to know in detail the behavior of ICUs vertically in medium-sized cities.

Keywords: Urban Heat Island. Drone. Local Climate Zones.

\section{Introdução}

As variáveis associadas ao clima urbano se constituem em dimensões do ambiente das cidades e seu estudo tem oferecido importantes contribuições ao equacionamento do planejamento urbano (Mendonça \& Assis, 2003). As variáveis do clima urbano são produzidas pela alteração da paisagem natural, por sua substituição por um ambiente construído, palco das intensas atividades humanas.

Um dos fenômenos mais evidentes da modificação climática causada por atividades antrópicas é a Ilha de Calor Urbana (ICU), que se manifesta através do aquecimento das áreas centrais das cidades em relação ao ambiente natural, tal como pontuam Arnfield (2003), Oke et al. (2017).

Oke (1982) define a ICU como uma anomalia térmica que tem dimensões horizontais, verticais e temporais e que se manifesta a partir de uma diferença térmica entre o centro e a periferia da área urbana durante períodos com atmosfera estável, ventos fracos, céu claro e intensa incidência de radiação solar.

As variações de temperatura do ar nas camadas intraurbanas de regiões de uma mesma cidade se tornam bem maiores com o aumento das intervenções humanas, principalmente em relação à supressão da vegetação, da canalização dos corpos d'água e aumento das áreas impermeabilizadas pela pavimentação urbana (Masiero \& Souza, 2018).

Diversos estudos buscaram compreender as causas, a relação com outros fatores e as consequências da formação de ICU. Em geral, tal fenômeno é causado pelas características dos elementos urbanos que modificam o balanço de energia e radiação (Oke, 1982; Stewart \& Oke, 2012).

Segundo Oke (1976), existem no mínimo duas diferentes camadas na ICU produzidas pelo efeito da urbanização. A primeira se trata de uma camada chamada de Urban Canopy Layer (UCL), que se estabelece abaixo do dossel urbano, norteada por processos atuantes em microescala, tendo sua consistência no ar contido entre os elementos de rugosidade urbana - materiais, geometria urbana e espaçamento entre os obstáculos. A segunda camada, denominada de Urban Boundary Layer (UBL), forma-se acima do dossel urbano, com seus processos ocorrendo em mesoescala. Este apontamento estabelece relação direta entre tamanho da cidade e intensidade das ICUs.

Muitos estudos de classificação de áreas urbanas têm sido realizados com técnicas de sensoriamento remoto, aos quais se baseiam na leitura de imagens térmicas captadas por satélites em resoluções, muitas vezes, insuficientes para discutir a complexidade de um tecido urbano. Naughton e McDonald (2019) avaliaram a variabilidade espacial da temperatura da superfície através de imagens térmicas em alta resolução capturadas por VANTs nas cidades de Milwaukee, Wisconsin e El Paso, Texas. Os resultados mostraram que os erros associados ao método de coleta de temperaturas de superfície podem ser de até $15,8^{\circ} \mathrm{C}$, sendo que a variabilidade pode ser influenciada pelas propriedades dos materiais de superfície, pelo tráfego e, principalmente, pela geometria urbana.

Quando somados à dinâmica espacial, à luz da pesquisa de Bornstein (1968), que trata do perfil vertical da ilha de calor, aplicada em Nova Iorque, indicam que a intensidade média do fenômeno ocorre em camadas próximas à superfície. A detecção de fenômenos associados às trocas de calor decorrentes da forma urbana, dos materiais, dos elementos naturais e do calor antropogênico ao nível do pedestre são fundamentais para a compreensão do comportamento temporal e espacial das ICUs, tal como evidencia Gartland (2010).

Uma forma aplicável para o estudo da paisagem urbana e para o estabelecimento de sua correlação com o clima local foi proposta por Stewart e Oke (2012), a qual prioriza os detalhes físicos de uma dada área urbana de estudos. Este método classifica os recortes urbanos de forma a padronizá-los através de parâmetros do espaço físico, chamando-os de Local Climate Zones (LCZs) ou Zonas Climáticas Locais (ZCLs) em tradução livre. 
Entre os diversos critérios para a classificação das áreas urbanas com o método das ZCLs, está o Fator de Visão do Céu (FVC) ou Sky View Fator, em inglês, que indica uma relação geométrica entre uma área de superfície terrestre e o céu visível em um determinado local. Outros parâmetros relevantes são compostos pela relação entre altura e largura dos cânions urbanos - H/W - à fração da superfície impermeável do solo, à proporção de área permeável do solo e à rugosidade dos elementos que compõem a paisagem.

A classificação da paisagem de forma padronizada pode facilitar a comparação de fenômenos microclimáticos, segundo Masiero \& Souza (2018), em diversas partes do mundo, no entanto, é necessário adquirir informações em número suficiente na malha urbana, tanto horizontal, quanto verticalmente, da variação da temperatura do ar, da temperatura radiante média, da umidade do ar, do vento e da incidência da radiação sobre as superfícies. A coleta de informações de variação de temperatura e umidade do ar para análises espaciais pode ser aprimorada com o uso de Veículo Aéreo Não Tripulado (VANT), devido a sua eficiência para registrar rapidamente informações de diversos pontos em um mesmo recorte urbano. Os sensores de registro de informações de temperatura do ar, acoplados a um sistema de GPS, permitem registrar detalhes das variações térmicas sobre uma cidade (Gaitani et al., 2017).

O uso de VANTs tem se destacado devido a sua facilidade de operação e seu baixo custo para os mais diversos segmentos, tanto nas áreas rurais quanto urbanas, tal como afirmam Brússolo et al. (2018). Conforme Gaitani et al. (2017), a integração de informações microclimáticas e balanço energético dos materiais no desenho urbano é essencial para enfrentar adequadamente os desafios relacionados às mudanças climáticas e à adaptação do ambiente.

As medições detectadas remotamente devem considerar a atmosfera intermediária e as propriedades radiativas da superfície que influenciam a emissão e a reflexão da radiação interna aos cânions urbanos.

Geralmente, as medições da temperatura do ar e de superfícies ao nível do pedestre são realizadas com transectos móveis ou com sensores em pontos fixos. Embora a precisão dos dados coletados in loco tenda a ser maior que a dos coletados por sensoriamento remoto, as dificuldades em trafegar pelas vias e o número limitado de pontos, muitas vezes, impossibilitam uma interpretação mais aprofundada dos fenômenos climáticos locais. Fabbria \& Costanzo (2020) propuseram o uso de VANTs para capturar imagens térmicas infravermelhas e medir a temperatura da superfície em Medicina, na Itália, e acordo com os autores, a aplicação desses procedimentos contribuiu para o aprimoramento e o detalhamento das informações em simulações computacionais de modelos microclimáticos.

Nessa evolução das pesquisas sobre a constituição e os efeitos das ICUs, é clara a observação da importância dos estudos sobre o tema, visto que métodos unidos a novas tecnologias podem agregar a importância de maior precisão das informações para o planejamento das cidades frente às alterações temporais e climáticas em ambiente urbano. Assim, a proposta deste trabalho é analisar o comportamento das ICUs entre a camada intraurbana e a camada limite da atmosfera sobre ZCLs, em Franca - SP, com o uso de um VANT. 


\section{Método}

O método de trabalho se resume a três etapas essenciais, sendo, em primeiro, a caracterização física genérica de porções representativas do tecido urbano de Franca - São Paulo, Brasil; em segundo, a aplicação de procedimentos de coleta dos dados de temperatura do ar através de um transecto móvel ao nível do pedestre e com o uso de um VANT em quatros dias de inverno. Em terceiro, o mapeamento dos dados, o tratamento estatístico, e a apresentação das ICUs em 35 pontos urbanos em quatro alturas: nível do pedestre, 30, 60 e 75 metros de altura, o que caracteriza a transição entre a camada intraurbana e a camada limite urbana. As etapas metodológicas estão discriminadas na figura 1.

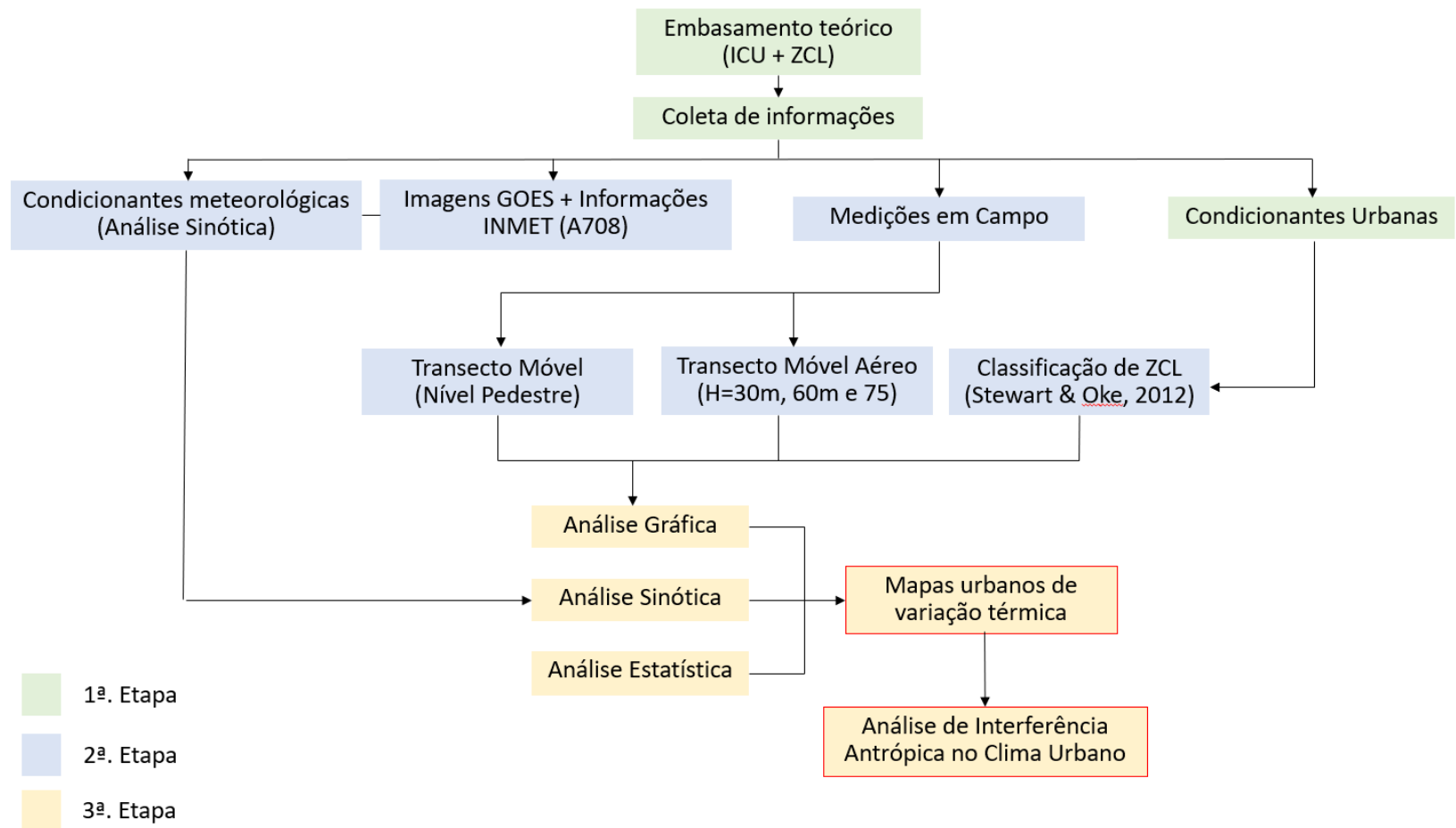

Figura 1 - Fluxograma dos procedimentos metodológicos. Fonte: Elaborado pelo autor principal: Otávio Megda.

\section{Critérios e caracterização dos pontos e dias de coleta}

Para registro da ocorrência das ICUs em Franca, SP as escolhas dos pontos de coleta dos dados de temperatura ar foram baseadas na proposta de Stewart e Oke (2012), sugerindo que a composição urbana deve ser levada em consideração na escolha das análises como causas do aquecimento noturno do ar.

Os pontos de coleta foram selecionados ao longo de um trajeto com destaques às características das ZCLs, sendo que 35 pontos de coletas na cidade - figura 2 - foram destacados e caracterizados. 


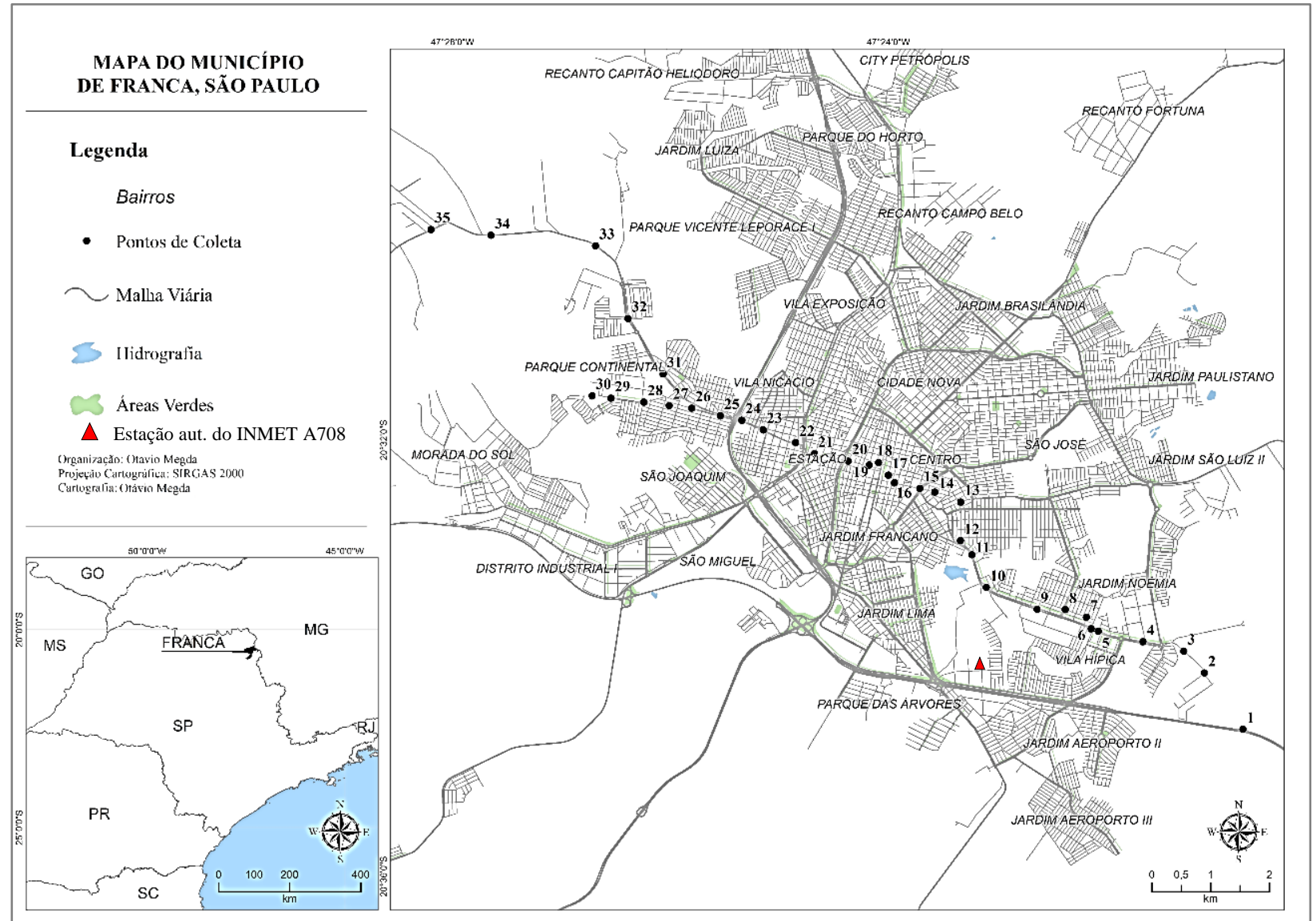

Figura 2 - Mapa do município de Franca - SP com o trajeto do VANT e os pontos das coletas do transecto móvel ao nível do pedestre realizadas em dias específicos do inverno de 2018. Fonte: Elaborado pelo autor principal: Otávio Megda.

Os recortes urbanos escolhidos tiveram como finalidade destacar a maior variedade espacial entre a composição espacial predominante no município, resgatando desde a ocupação na zona rural, passando por áreas periféricas residenciais até as áreas mais adensadas da região central. Os principais parâmetros teóricos e técnicos aplicados para a classificação foram o FVC, a relação H/W, a superfície construída e a altura média da rugosidade. A composição dos parâmetros espaciais consta na figura 3.

Ainda, foram obtidos dados como direção dos ventos e temperatura ar a partir da estação meteorológica A-708 do Instituto Nacional de Meteorologia (INMET) - instalada na Região Sul da cidade, na zona rural, como referência para as análises com os dados horários pertinentes ao intervalo de 1 hora na mensuração dos dados com o transecto. Sendo assim, foi feita uma comparação dos valores horários obtidos na coleta móvel (transecto e VANT) com os valores da estação meteorológica A-708, a fim de apresentar as variações térmicas entre os diferentes pontos e altitudes, expressas pelas equações: $\Delta$ Temperatura rural urbano (nível do pedestre); $\Delta$ Temperatura rural - urbano (30 metros de altura); $\Delta$ Temperatura rural urbano (60 metros de altura) e $\Delta$ Temperatura rural - urbano (75 metros de altura). 
Análise das Ilhas de Calor Urbano sobre Zonas Climáticas Locais com o uso de VANT

- Veículo Aéreo Não Tripulado - em uma cidade média

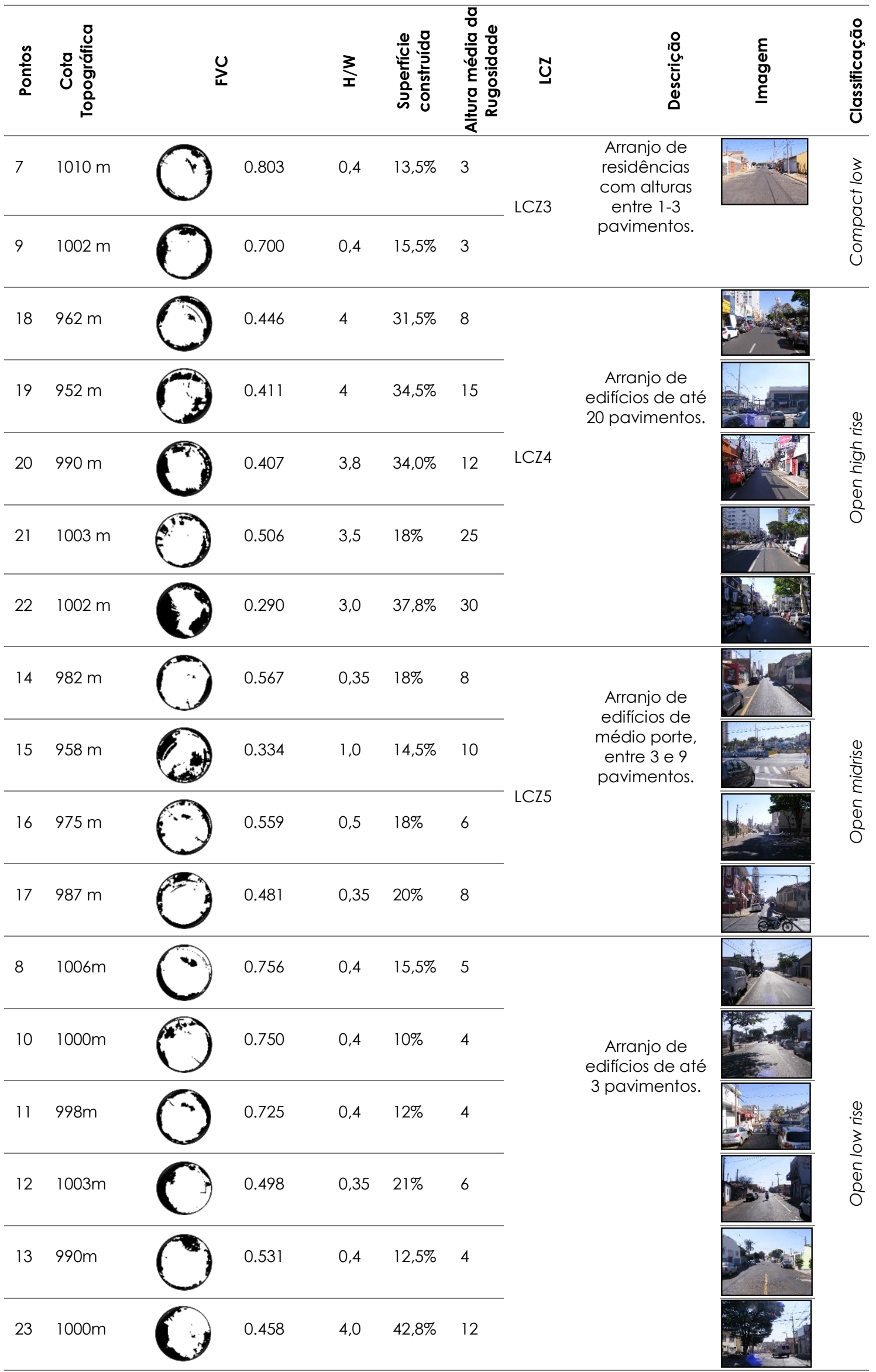

Figura 3 - Classificação das Zonas Climáticas Locais dos pontos monitorados. Fonte: Adaptado de Stewart e Oke (2012). 


\section{Instrumentação e Coleta dos dados}

A operação de voo foi amparada pela legislação vigente, já que no Brasil o uso de VANT, sobretudo na área urbana, passou a ter autorização legal, de acordo com a portaria no 415/2015, do Departamento de Controle do Espaço Aéreo (DCEA) do Ministério da Defesa (Brasil, 2015b), a qual aprovou a regulamentação do Sistema de Aeronaves Remotamente Pilotadas (RPA - sigla em inglês) e o acesso ao espaço aéreo brasileiro, em conformidade com o previsto no Decreto no 6.834/2009 (Brasil, 2009), autorizado pela Agência Nacional de Aviação Civil (ANAC). A ANAC definiu regras para as operações civis de VANTs em maio de 2017, tal como aponta Brasil (2017a), sob o Regulamento Brasileiro de Aviação Civil Especial (RBAC), de no 94/2017 (Brasil, 2017b), aprovado pela Resolução no 419/2017 (Brasil, 2017c), que orienta e regulamenta o uso destes aparelhos, apresentando especificações, procedimentos legais, técnicos e operacionais dos VANTs.

0 equipamento para o transecto móvel foi acoplado em um suporte de madeira com um termohigrômetro digital da marca IncoTerm e posicionado a 1,5m de altura do solo. 0 sensor do termômetro foi protegido da influência da radiação com um abrigo meteorológico, tal como mostra a figura 4 (a e b). 0 trajeto levou 1 hora e foi realizado no sentido sudeste noroeste, com um percurso de pouco mais de 17,5 quilômetros.

Com o VANT, foi possível registrar a variação de temperatura do ar na transição entre a camada intraurbana e a camada limite urbana, ou seja, entre 30, 60 e 75 metros de altura do solo, com um termohigrômetro tipo hobo U23 (figura 5) em cada um dos pontos elencados. As medições foram realizadas entre 16h até no máximo 17h, durante os dias 03, 04, 05 e 06 de julho de 2018, totalizando 4 dias de coleta.

a)

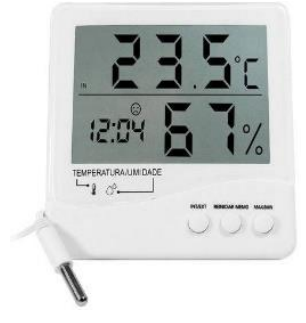

b)

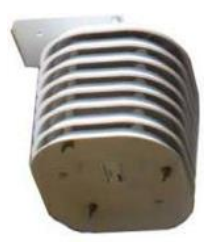

Figura 4 - a) Sensor de temperatura do ar fixado na haste de coleta e b) abrigo meteorológico. Fonte: Adaptado de Incoterm (2018).

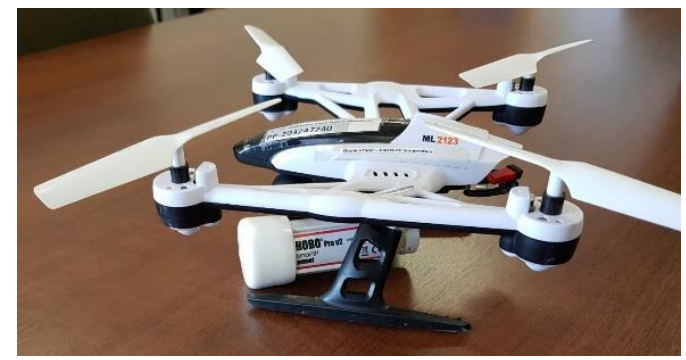

Figura 5 - VANT (Drone) com o Hobo U23 acoplado na parte inferior. Fonte: autores (2018).

O VANT, em cada ponto de captação, foi elevado para a altura de 30, 60 e 75 metros, permanecendo por 1 minuto suspenso em cada nível. Devido ao tempo de carga da bateria do VANT, foi possível registrar conjuntos de seis pontos a cada 12 minutos de voo, e assim finalizar o trajeto de acordo com a necessidade de substituição das baterias durante o experimento.

Concomitante a esses dados, foram comparados com o valor horário captado pelo Estação do INMET, na mesma janela horária utilizada para a captação com o VANT.

Os 35 pontos analisados tiveram ainda o uso de um GPS - Global Position System - acoplado ao VANT para georreferenciar o trajeto e os pontos, e compor as cartas bases com as específicas coordenadas. 
A fim de compreender os sistemas atmosféricos atuantes no período selecionado, foram levadas em consideração as cartas sinóticas, disponíveis pelo Centro de Previsão de Tempo e Estudos Climáticos (CPTEC) do Instituto Nacional de Pesquisas Espaciais (INPE, 2018b) e as imagens de Satélite GOES de 2018 (INPE, 2018a).

\section{Tratamento e mapeamento dos dados}

Para a produção dos mapas base e das cartas georreferenciadas, foi utilizado o software QGis ${ }^{1}$, versão 2.18. Para tratamento dos dados e análise dos resultados, foram elaboradas cartas de isotermas através do Software Surfer ${ }^{2}$ e ArcMap ${ }^{3}$, permitindo assim a visualização das diferentes áreas e pontos coletados, com a variação de temperatura do ar nos três níveis.

Os valores de temperatura do ar coletados ponto a ponto foram armazenados para a geração dos mapas isotérmicos. Foi inserida a carta base do município de Franca, SP, a partir da base do Instituto Brasileiro de Geografia e Estatística (IBGE, 2010). A carta foi georreferenciada - desenvolvida -no ArcGis® e inserida à malha urbana com a divisão de bairros, a partir de arquivos dispostos na página oficial da Prefeitura Municipal de Franca (2014).

Como critério de raio de abrangência a ser considerado nas medições e produções cartográficas e parâmetros variáveis de análises, foram levados em consideração os estudos de Debiazi (2016), que considerou diferentes raios de abrangência horizontalmente (25, 50 e 100 metros) em análises térmicas realizadas em São Carlos, SP, tendo como parâmetros variáveis de análises, Coeficiente de Ocupação; Vegetação; FVC e Coeficiente de Cobertura de Solo em diferentes raios. Nesta pesquisa, o raio de abrangência do FVC com melhor influência e desempenho foi o de 100 metros, sendo este o padrão adotado para a criação dos mapas.

Foram gerados, portanto, 4 mapas isotérmicos, referentes aos dias de coleta que apresentam graficamente os dados térmicos e consolidam os pontos georreferenciados, permitindo assim a visualização da variação da temperatura do ar nos diferentes pontos da cidade, em 4 alturas diferentes: nível do pedestre (transecto móvel), 30, 60 e 75 metros (VANT).

Esses dados foram comparados aos dados obtidos nas coletas da Estação Automática A-708 do INMET, gerando um valor de ICU resultante destas comparações entre a temperatura do ar no ambiente rural e temperatura do ar nos 35 pontos na cidade. Os resultados de ocorrência de ICU foram trabalhados de modo a relacionar linearmente os parâmetros físicos das ZCLs ao FVC e à relação altura/largura H/W dos 35 pontos nas 4 alturas. Assim, foi possível verificar quais características físicas do ambiente urbano representam maior impacto às condições microclimáticas ao longo do trajeto estudado.

\section{Resultados e discussões}

\section{Resultados das análises das coletas do período de Inverno de 2018}

As coletas de inverno de 2018 foram realizadas nos dias 3, 4, 5 e 6 de julho (4 dias), diante de condições sinóticas que se demonstraram favoráveis, como baixa quantidade de nuvens baixas, vento médio de 2 a 6 $\mathrm{km}, 72 \%$ destes vindo da direção Sudeste para Noroeste. 0 quadro sinótico ao longo dos dias pesquisados nesse período foi quase que totalmente estável. As condições de baixa nebulosidade da atmosfera permitiram a coleta dos dados ao longo dos dias, conforme relatam Amorim (2017), Ugeda (2011), Mills (2006), Masiero \& Souza (2018), Gartland (2010), Kruger \& Drach (2017) e Tavares (2020).

\footnotetext{
${ }^{1}$ QGis é um free software disponível para produção e manuseio de cartas, registrado por Free Software Foundation.

2 Surfer é marca registrada da Golden Software, Inc.

${ }^{3}$ ArcMap é componente integrante do Software ArcGis, marca registrada da Esri Software, Inc.
} 
A figura 6 contém as cartas sinóticas do período - a, b, c, d - correspondentes, respectivamente, aos dias 03, 04, 05 e 06 de julho de 2018, como recorte de amostragem dos dados.

A análise sinótica do período evidenciou uma atuação de sistemas frontais, com pouca atuação de vento e estabilidade meteorológica.

a)

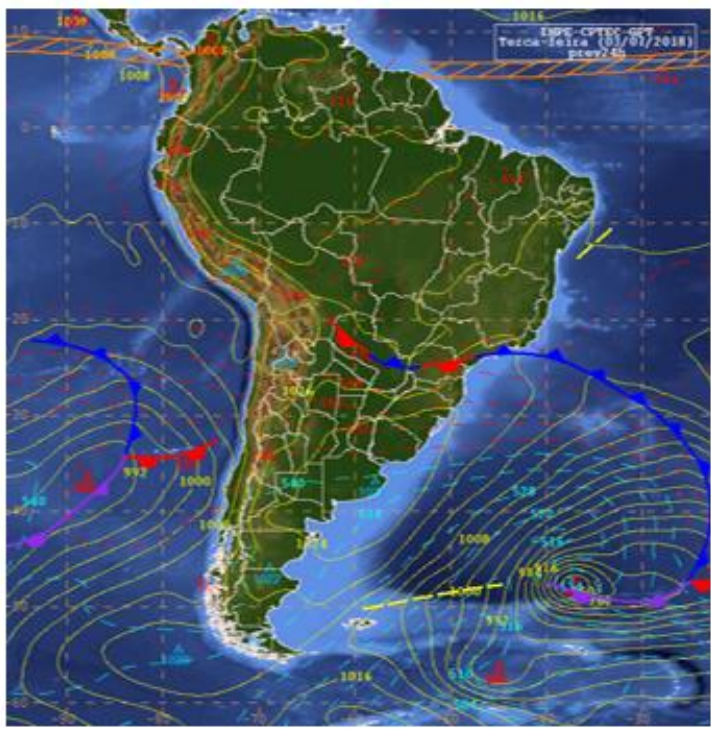

C)

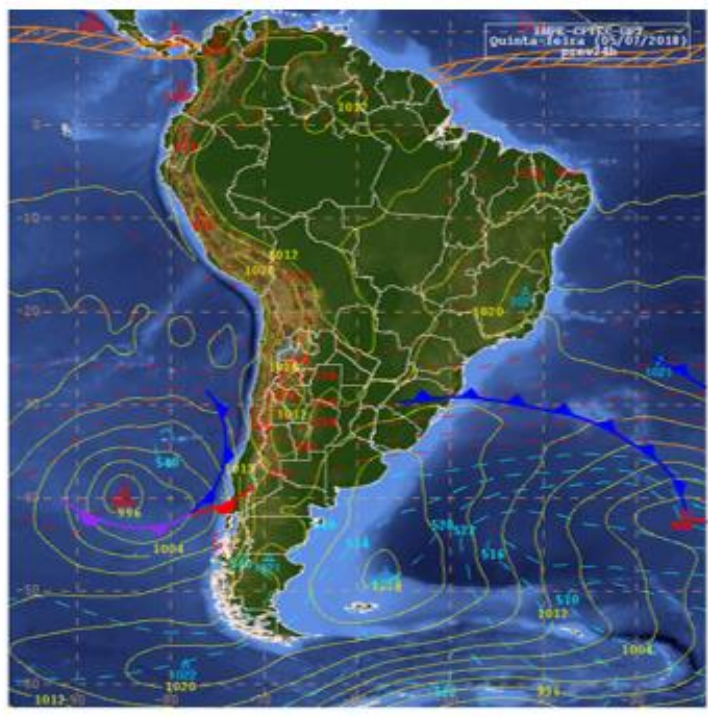

b)

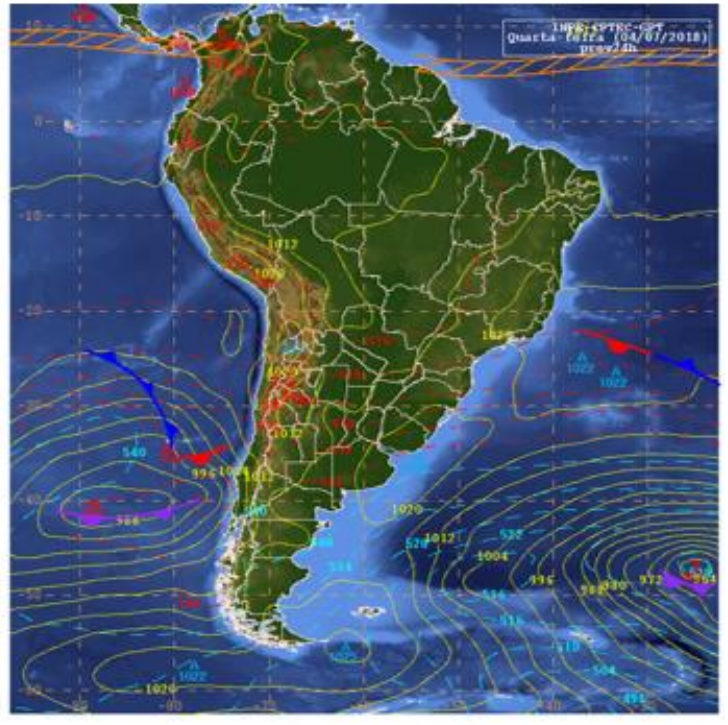

d)

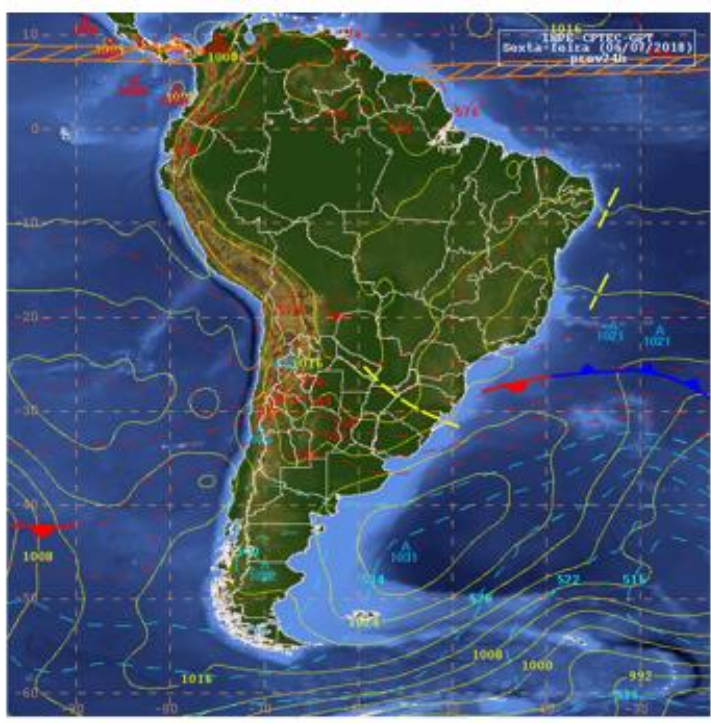

Figura 6 - Cartas sinóticas da América do Sul com os sistemas atmosféricos atuantes entre os dias 03 e 06 de julho de 2018. Fonte: INPE, 2018a, 2018b.

Os resultados das medições, expressas pelas diferenças das temperaturas do ar obtidas com a rede fixa de estações meteorológicas do INMET, destacadas a variação $(\Delta)$ das temperaturas rural $\rightarrow$ urbana (ao nível do pedestre, 30, 60 e 75 metros de altura), calculados pelas médias dos 4 dias de coletas, nas respectivas alturas de cada ponto, estão expostos na tabela 1. 
Análise das Ilhas de Calor Urbano sobre Zonas Climáticas Locais com o uso de VANT

- Veículo Aéreo Não Tripulado - em uma cidade média

Tabela 1 - $\Delta$ das temperaturas registradas durante os dias de coleta em campo no inverno de 2018

\begin{tabular}{|c|c|c|c|c|c|c|}
\hline Ponto & LCZ & Horário & $\begin{array}{l}\Delta \text { Temp } \\
\text { rural } \rightarrow \text { urbano } \\
\text { Nível pedestre }\left({ }^{\circ} \mathrm{C}\right)\end{array}$ & $\begin{array}{l}\Delta \text { Temp } \\
\text { rural } \rightarrow \text { urbano } \\
30 \mathrm{~m}\left({ }^{\circ} \mathrm{C}\right)\end{array}$ & $\begin{array}{l}\Delta \text { Temp } \\
\text { rural } \rightarrow \text { urbano } \\
60 \mathrm{~m}\left({ }^{\circ} \mathrm{C}\right)\end{array}$ & $\begin{array}{l}\Delta \text { Temp } \\
\text { rural } \rightarrow \text { urbano } \\
75 \mathrm{~m}\left({ }^{\circ} \mathrm{C}\right)\end{array}$ \\
\hline $\mathrm{Pl}$ & 9 & $16 \mathrm{~h} 02 \mathrm{~min}$ & 1,27 & $-0,83$ & $-2,93$ & $-4,33$ \\
\hline P2 & 9 & $16 \mathrm{~h} 04 \mathrm{~min}$ & 1,77 & $-0,73$ & $-3,03$ & $-3,93$ \\
\hline P3 & 9 & $16 \mathrm{~h} 07 \mathrm{~min}$ & 1,87 & $-0,13$ & $-3,13$ & $-3,93$ \\
\hline P4 & 9 & $16 \mathrm{~h} 09 \mathrm{~min}$ & 3,37 & 2,37 & $-1,63$ & $-3,03$ \\
\hline P5 & 9 & $16 \mathrm{hl} 1 \mathrm{~min}$ & 5,77 & 3,07 & $-1,93$ & $-2,63$ \\
\hline P6 & 9 & $16 \mathrm{~h} 13 \mathrm{~min}$ & 6,47 & 5,07 & $-1,63$ & $-2,93$ \\
\hline P7 & 3 & $16 \mathrm{hl} 6 \mathrm{~min}$ & 6,27 & 2,87 & 0,07 & $-3,03$ \\
\hline P8 & 6 & 16h19min & 6,47 & 4,97 & 2,07 & $-2,33$ \\
\hline P9 & 3 & $16 \mathrm{~h} 22 \mathrm{~min}$ & 6,37 & 1,07 & $-0,63$ & $-4,13$ \\
\hline P10 & 6 & $16 \mathrm{~h} 24 \mathrm{~min}$ & 6,77 & 1,07 & $-0,93$ & $-4,03$ \\
\hline P11 & 6 & $16 \mathrm{~h} 25 \mathrm{~min}$ & 6,67 & 1,67 & $-1,03$ & $-3,03$ \\
\hline P12 & 6 & $16 \mathrm{~h} 26 \mathrm{~min}$ & 6,87 & 4,87 & $-1,93$ & $-3,13$ \\
\hline $\mathrm{P} 13$ & 6 & $16 \mathrm{~h} 28 \mathrm{~min}$ & 6,77 & 4,97 & $-2,03$ & $-4,13$ \\
\hline $\mathrm{P} 14$ & 5 & $16 \mathrm{~h} 29 \mathrm{~min}$ & 6,97 & 5,07 & $-2,63$ & $-4,93$ \\
\hline P15 & 5 & $16 \mathrm{~h} 30 \mathrm{~min}$ & 7,07 & 4,97 & $-1,63$ & $-5,03$ \\
\hline P16 & 5 & $16 \mathrm{~h} 32 \mathrm{~min}$ & 7,27 & 5,07 & $-1,93$ & $-4,93$ \\
\hline P17 & 5 & $16 \mathrm{~h} 33 \mathrm{~min}$ & 7,37 & 5,47 & $-0,33$ & $-2,93$ \\
\hline P18 & 4 & $16 \mathrm{~h} 35 \mathrm{~min}$ & 7,37 & 5,67 & $-0,53$ & $-2,63$ \\
\hline P19 & 4 & $16 \mathrm{~h} 36 \mathrm{~min}$ & 7,47 & 5,07 & $-0,03$ & $-2,23$ \\
\hline P20 & 4 & $16 \mathrm{~h} 38 \mathrm{~min}$ & 7,47 & 6,07 & $-0,93$ & $-2,73$ \\
\hline P21 & 4 & $16 \mathrm{~h} 40 \mathrm{~min}$ & 7,47 & 5,97 & $-0,63$ & $-2,73$ \\
\hline P22 & 4 & $16 \mathrm{~h} 41 \mathrm{~min}$ & 7,67 & 5,57 & $-0,93$ & $-2,63$ \\
\hline P23 & 6 & $16 \mathrm{~h} 42 \mathrm{~min}$ & 7,07 & 5,37 & $-2,03$ & $-3,13$ \\
\hline P24 & 6 & $16 \mathrm{~h} 42 \mathrm{~min}$ & 7,17 & 2,97 & $-1,63$ & $-3,13$ \\
\hline P25 & 6 & $16 \mathrm{~h} 43 \mathrm{~min}$ & 7,27 & 2,97 & $-1,53$ & $-3,33$ \\
\hline P26 & 6 & $16 \mathrm{~h} 45 \mathrm{~min}$ & 7,17 & 3,37 & $-0,93$ & $-2,73$ \\
\hline P27 & 6 & 16 h47min & 6,87 & 3,57 & $-1,23$ & $-2,93$ \\
\hline P28 & 6 & $16 \mathrm{~h} 48 \mathrm{~min}$ & 6,87 & 4,07 & $-1,63$ & $-2,63$ \\
\hline P29 & 6 & $16 \mathrm{~h} 50 \mathrm{~min}$ & 6,47 & 2,67 & $-2,93$ & $-2,93$ \\
\hline P30 & 6 & $16 \mathrm{~h} 51 \mathrm{~min}$ & 6,27 & 2,37 & 0,07 & $-3,23$ \\
\hline P31 & 6 & $16 \mathrm{~h} 51 \mathrm{~min}$ & 4,67 & 1,07 & $-0,93$ & $-3,63$ \\
\hline P32 & 6 & $16 \mathrm{~h} 53 \mathrm{~min}$ & 4,07 & $-0,73$ & $-2,33$ & $-4,13$ \\
\hline P33 & 9 & $16 \mathrm{~h} 54 \mathrm{~min}$ & 3,17 & $-0,93$ & $-3,73$ & $-4,53$ \\
\hline P34 & 9 & $16 \mathrm{~h} 56 \mathrm{~min}$ & 3,47 & $-0,83$ & $-3,93$ & $-5,13$ \\
\hline P35 & 9 & $16 \mathrm{~h} 58 \mathrm{~min}$ & 2,37 & $-0,63$ & $-4,13$ & $-5,73$ \\
\hline
\end{tabular}

Fonte: Elaborado pelo autor principal: Otávio Megda.

As coletas dos dados ao nível do pedestre deixaram claro a formação de pontos com temperaturas mais elevadas na camada intraurbana, sendo que as amplitudes térmicas entre os diversos pontos apresentam valores acima de $6^{\circ} \mathrm{C}$, com exceção das áreas periféricas, as quais se caracterizam por ser ambientes de transição entre áreas urbanas e rurais e possuir menor densidade construída. A maior diferença de temperatura registrada entre o ambiente rural e o urbano atingiu $7,6^{\circ} \mathrm{C}$ no ponto 22 no dia 4 de julho. Este ponto da cidade é caracterizado pela predominância de edifícios de até 20 pavimentos, que resultam um FVC de 0,29 com muitas superfícies de concreto, asfalto, coberturas metálicas e é classificado como LCZ4.

Diante dos valores nos pontos coletados, do ponto 5 até o 3, houve uma pequena oscilação de ICU. A figura 7 mostra a diferença de temperatura do ar entre os pontos mensurados em comparação com a estação fixa do INMET - A-708, obtida de acordo com o INMET (2018), instalada na zona rural da cidade de Franca, ao nível do pedestre, a 30, 60 e 75 metros de altura, a qual expressa a variação entre a temperatura do ar no ambiente rural e urbano, $\Delta \mathrm{T}$ rural $\rightarrow$ urbano.

Os pontos da região central (pontos 17 ao 22) representam as maiores ICUs, consequentemente, indicam mais elevadas temperaturas do ar ao nível do pedestre. 


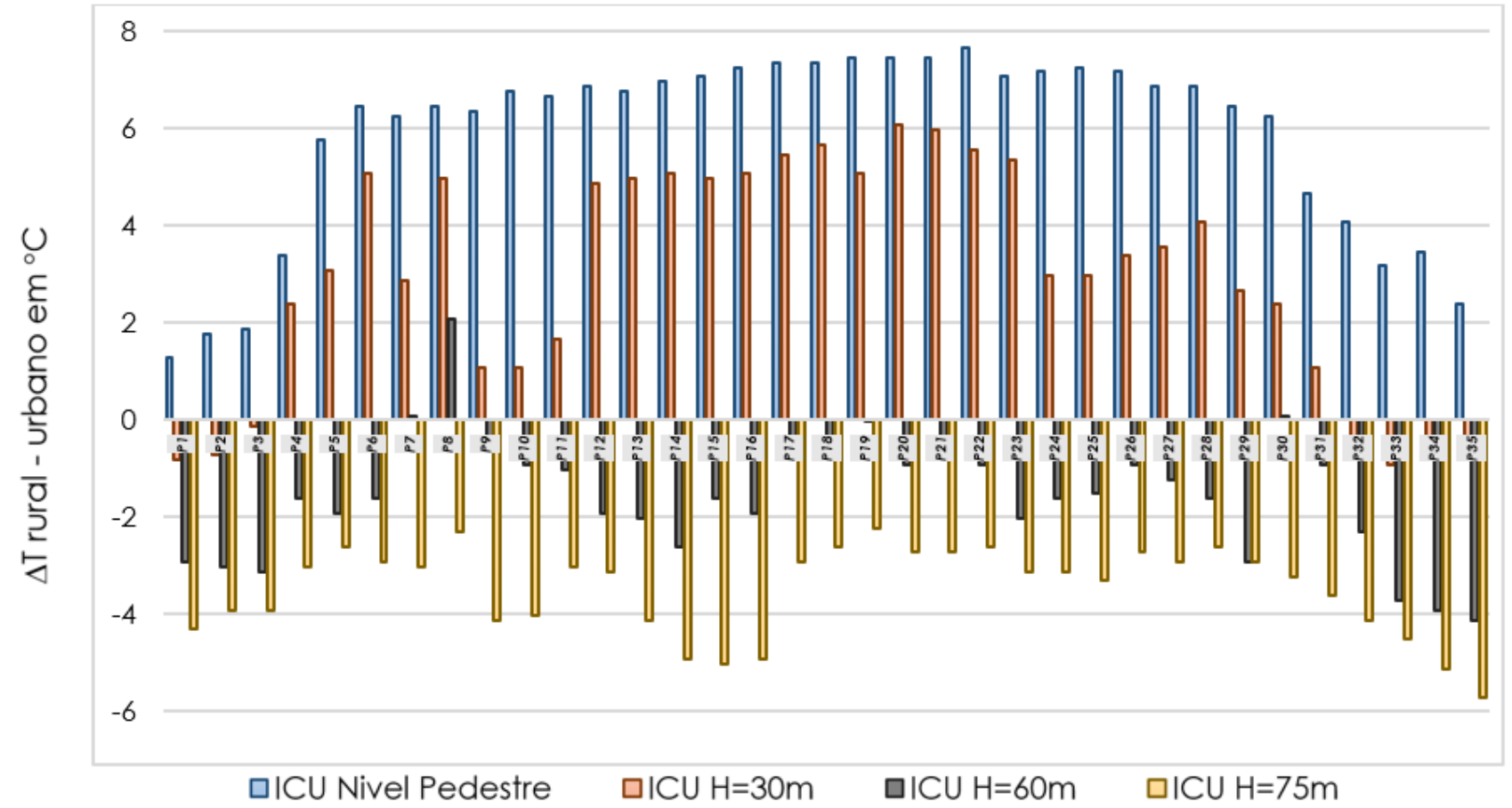

Figura 7 - $\Delta \mathrm{T}$ rural $\rightarrow$ urbano em ${ }^{\circ} \mathrm{C}$ das ICUs aos níveis do pedestre, a 30, 60 e 75 metros de altura. Fonte: Elaborado pelo autor principal: Otávio Megda.

Observa-se também que as temperaturas acima da camada limite intraurbana, em geral, são inferiores à temperatura de referência registrada próxima à superfície da área rural, de forma que a ação da configuração urbana influencia fortemente a temperatura do ar na camada intraurbana. É possível verificar que à medida que o VANT se eleva sobre a cidade, a influência da composição urbana se reduz gradativamente na temperatura do ar.

As figuras 8, 9, 10 e 11 apresentam a relação linear entre a variação de ICU e o FVC dos 35 pontos avaliados na área urbana ao nível do pedestre, a 30,60 e 75 metros de altura. Observa-se uma relação entre a ocorrência de ICU e o FVC representada pelo valor de $\mathrm{R}^{2}$ de 0,2436 na figura 8 ao nível do pedestre, onde as maiores variações térmicas estão entre os pontos 17 ao 20 , sendo que o ponto 17 está disposto na LCZ5 e os pontos 18, 19 e 20 na LCZ4.

A figura 9 apresenta a relação linear entre a variação da ICU e o FVC a 30 metros de altura, próxima à camada limite urbana. Os valores evidenciaram uma relação linear de $\mathrm{R}^{2} 0,202$, considerada fraca.

Diante do trajeto analisado, os pontos 14 ao 23 registraram variações de ICU entre $5^{\circ} \mathrm{C} \mathrm{e} 6^{\circ} \mathrm{C}$ a 30 metros de altura, sendo esses pontos pertencentes às LCZs 4, 5 e 6. Nas áreas rurais, caracterizadas por LCZ9, nos pontos $1,2,3,33,34$ e 35, foi registrada pouca variação de temperatura, sendo que, em alguns casos, a diferença foi de até $-0,9^{\circ} \mathrm{C}$.

Os valores relacionados de ICU e FVC registrados a 60 metros de altura geraram uma um valor de $\mathrm{R}^{2}$ 0,0016, o que também indica uma fraca influência do ambiente urbanizado acima da camada limite urbana.

Os pontos 34 e 35, LCZ9, na região periférica mostraram as maiores diferenças de temperatura do ar entre o ambiente urbano e o rural, próxima de $-4^{\circ} \mathrm{C}$ a 60 metros de altura.

Os valores demonstrados na figura 11, de dados relacionados de ICU e FVC registrados a 75 metros de altura, deram a possibilidade de análise de um valor de $\mathrm{R}^{2}$ 0,0097, o que indica uma diminuição ainda maior da influência do ambiente urbanizado acima da camada limite urbana. 


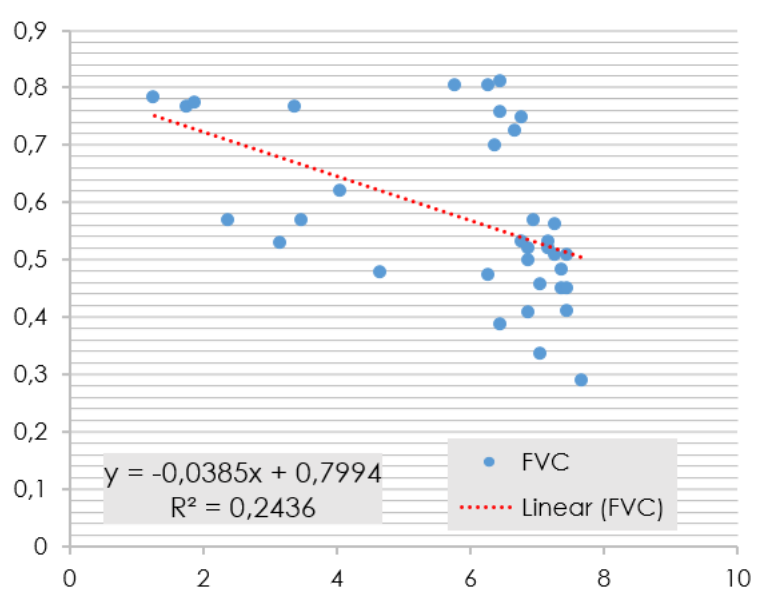

Figura 8 - Relação linear entre $\Delta \mathrm{T}$ ICU X Fator de visão do céu (FVC) à nível do pedestre. Fonte: Elaborado pelo autor principal: Otávio Megda.

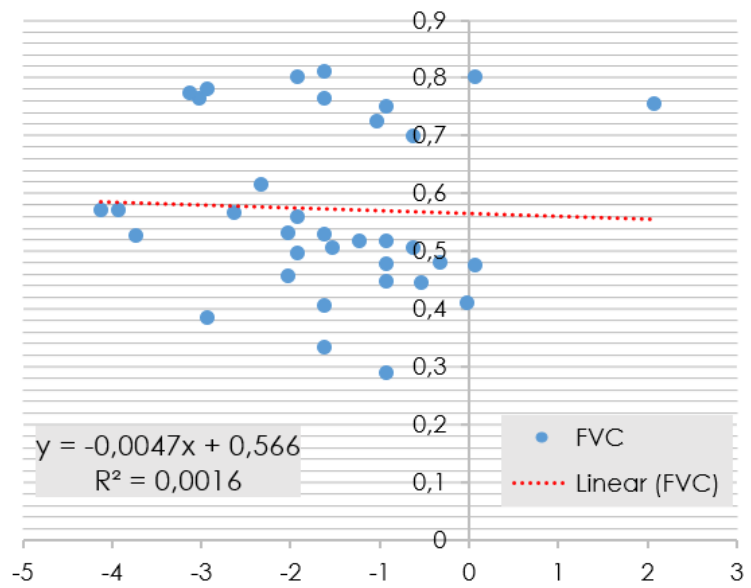

Figura 10 - Relação linear entre $\triangle T$ ICU X FVC a 60 metros de altura. Fonte: Elaborado pelo autor principal: Otávio Megda.

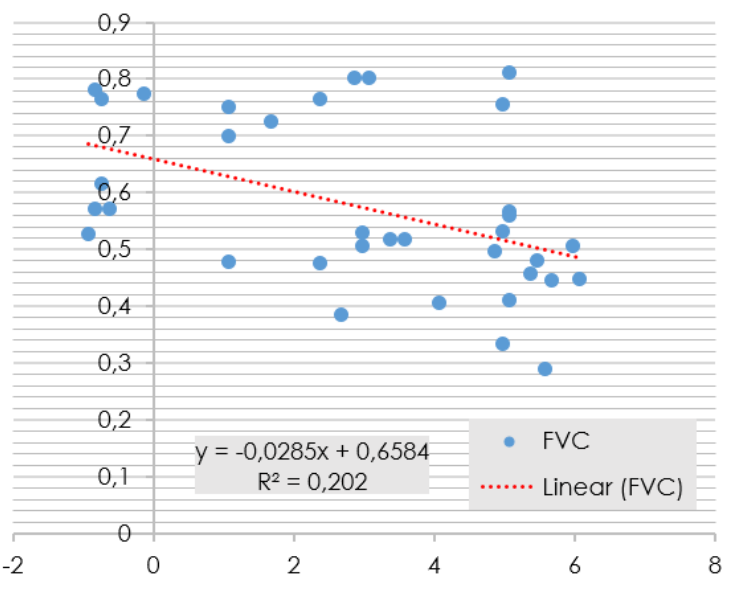

Figura 9 - Relação linear entre $\Delta \mathrm{T} I \mathrm{CU}$ x FVC a 30 metros de altura. Fonte: Elaborado pelo autor principal: Otávio Megda.

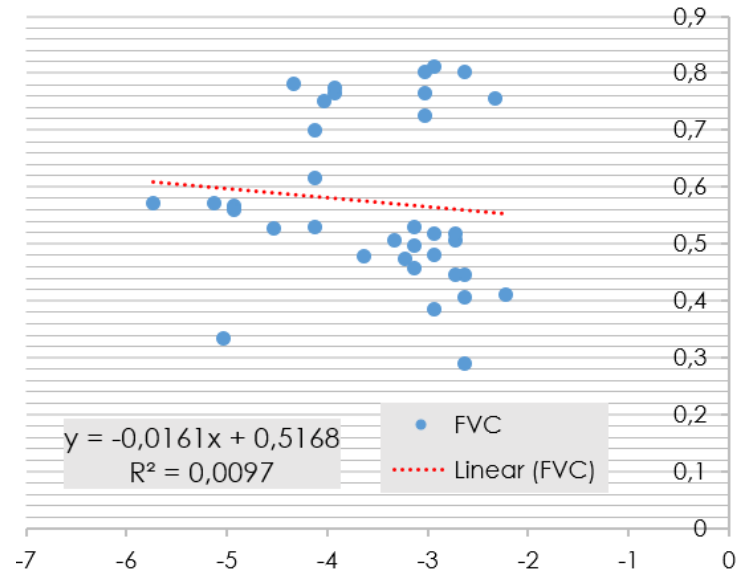

Figura 11 - Relação linear entre $\Delta \mathrm{T}$ ICU X FVC à 75metros de altura. Fonte: Elaborado pelo autor principal: Otávio Megda.

É possível detectar que as relações mais elevadas entre intensidade de ICU com o FVC ocorrem próximas à superfície, o que indica a forte influência da geometria urbana e da refletância dos materiais das superfícies sobre o clima urbano, conforme relatam Mills (2006), Kruger \& Drach (2017), Assis et al. (2017), Ferreira \& Duarte (2019), Naughton et al. (2019).

À medida que o VANT se eleva, é possível verificar valores de ICU inferiores aos registrados próximos à superfície, sendo que os valores de relação são mais baixos acima da camada limite urbana do que na camada intraurbana. Tal constatação indica uma leve perda de precisão no registro dos fenômenos microclimáticos, devido à provável influência das massas de ar continentais, conforme relatam Brússolo \& Vecchia (2019), da dissipação do calor e da ação da refletância das coberturas das edificações, conforme Muniz-Gäal et al. (2020) e Galusic \& Dornelles (2017).

A figura 12 apresenta a média dos dias analisados na pesquisa com o uso do transecto móvel para coleta de temperatura do ar ao nível do pedestre. Os pontos 15 e 20, LCZ4 e 5, encravados no fundo de vale dos dois principais córregos da cidade, apresentaram valores de ICU de $7,0^{\circ} \mathrm{C}$ e $7,50^{\circ} \mathrm{C}$, respectivamente. Os elevados índices de ICU registrados em fundos de vale podem demonstrar o efeito de barreira aos ventos provocados pelo relevo e pelo ambiente construído. 


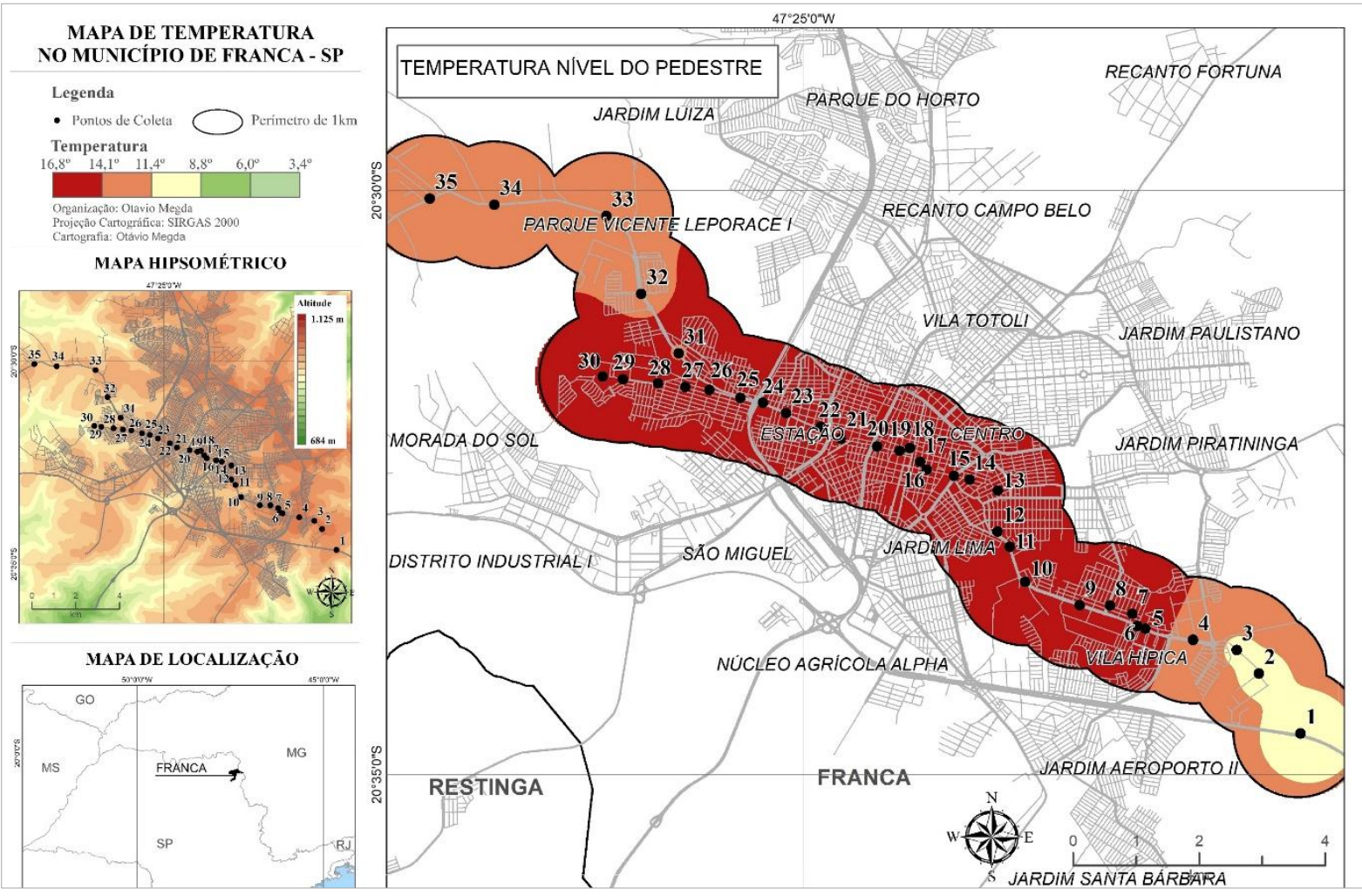

Figura 12 - Mapa com as temperaturas médias do ar ao nível do pedestre em Franca - SP durante os dias de coleta em julho de 2018 com o transecto móvel. Fonte: Elaborado pelo autor principal: Otávio Megda.

A figura 13 apresenta a composição urbana do ponto 22, o qual apresentou o maior índice de ICU de $7,67^{\circ} \mathrm{C}$.

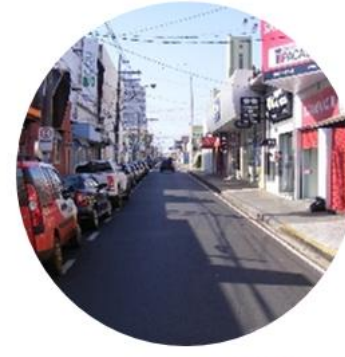

Vista do ponto 22 ao nivel do pedestre.

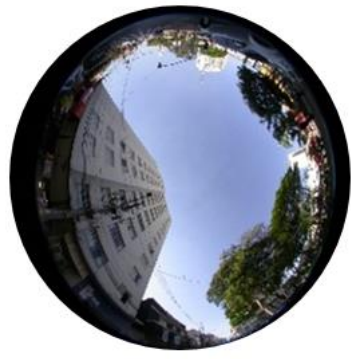

Vista com Fish eve FVC 0,290

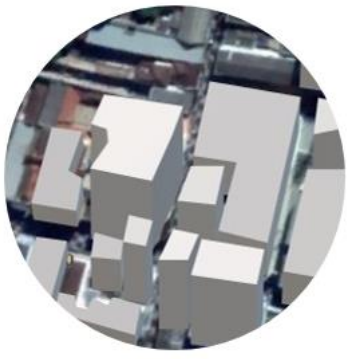

Vista aérea do ponto 22

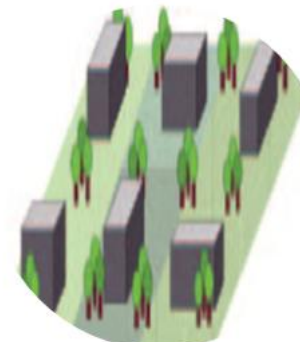

ZCL 5 - Stewart \& Oke, 2012

Figura 13 - Representação gráfica do ponto 22 ao nível do solo. Fonte: Elaborado pelo autor principal: Otávio Megda.

Seu conjunto construído destaca-se em arranjos espaciais abertos de edifícios de médio porte (3-9 andares) e uma vegetação escassa. Sendo assim, o fator de limitação horizontal fica em 71\%, congruente ao tipo de materiais utilizados nas coberturas de solo. A área entraria na classificação "E" dos tipos de cobertura de solos propostos por Stewart e Oke (2012), sendo predominantemente com pavimento impermeável.

A paisagem do ponto 22 evidencia caracteristicamente a área pavimentada com pouca ou nenhuma vegetação, logo, a concentração de calor registrada ao nível do solo e também a 30 metros de altura - figura 14 - com o uso do VANT, evidencia nesse ponto a abóbada da ilha de calor registrada nesta série.

Do ponto 14 até $\mathrm{o} 23$, as ICUs oscilaram entre $5,0^{\circ} \mathrm{C}$ e $6,0^{\circ} \mathrm{C}$, ou seja, a irradiação do calor das superfícies urbanas ainda pode ser percebida, porém, em menor intensidade. Os pontos 1, 2, 3, 32, 33, 34 e 35 tiveram valores de ICU de até $-0,93^{\circ} \mathrm{C}$, visto que estas áreas descritas se encaixam na ZCL 9 - área com construções escassas - e com tipo de cobertura de solo variado entre solo nu ou areia (F) ou árvores dispersas (B). As 
configurações urbanas destes pontos, com fartas áreas abertas, poucas construções e alta circulação de vento na superfície, favoreceram o baixo índice de ocorrência de ICU.

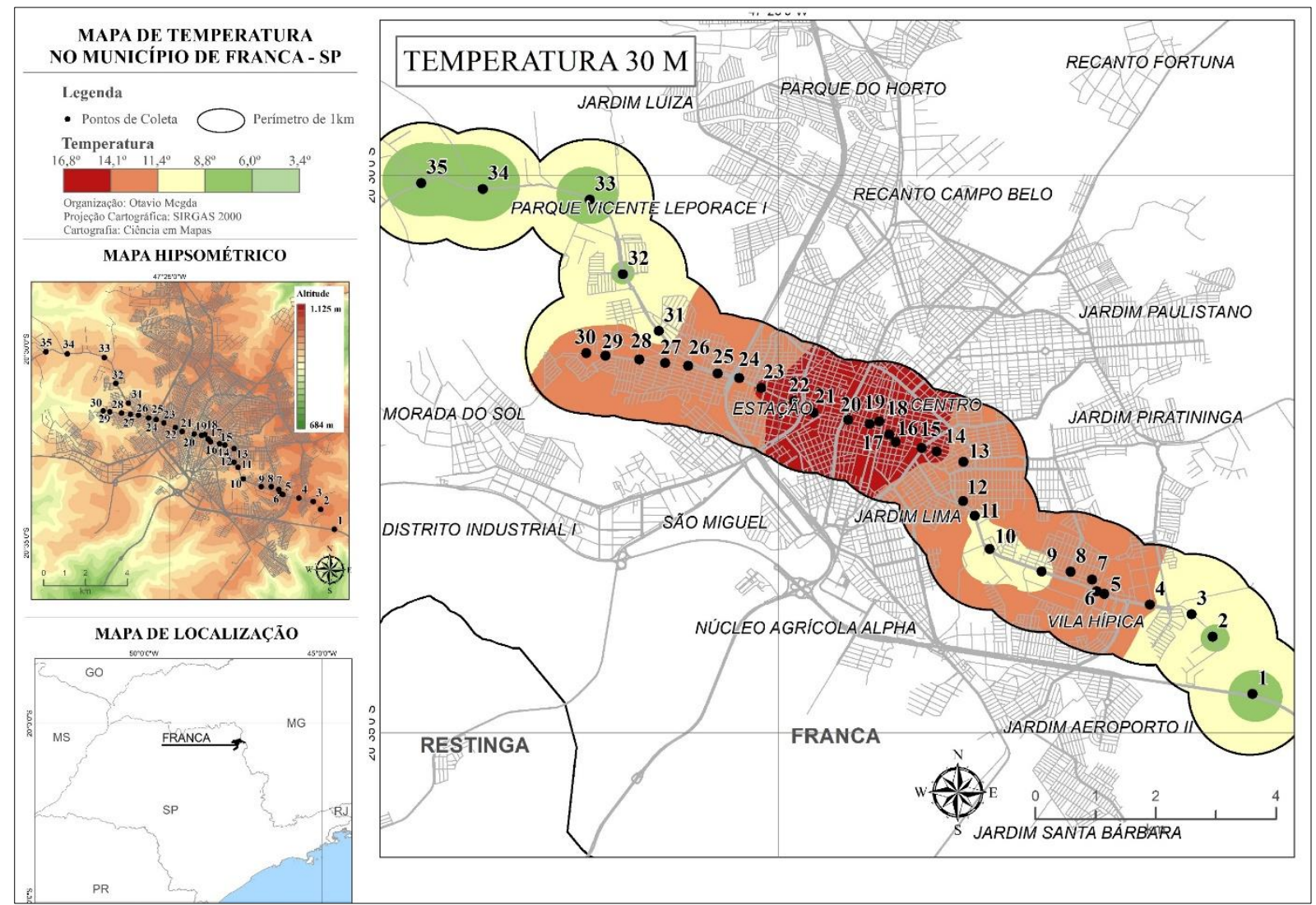

Figura 14 - Mapa com temperaturas médias a 30 metros de altura em Franca - SP durante os dias de coleta em julho de 2018 com uso do VANT. Fonte: Elaborado pelo autor principal: Otávio Megda.

Na figura 15, que demonstra as temperaturas obtidas a 60 metros do nível do solo, as temperaturas ainda sofrem com o impacto do calor gerado pelas áreas urbanizadas, como nos pontos 7, 8 e 9. Uma das construções mais altas da cidade localiza-se numa área de encontro de vertente, sendo uma das cotas mais baixas da área urbana.

A figura 15 apresenta ainda a variação de temperatura do ar ao longo do transecto a 60 metros de altura. As temperaturas absolutas do ar variaram entre $3,4^{\circ} \mathrm{C}$ e $8,8^{\circ} \mathrm{C}$ predominantemente ao longo de todo o percurso, e os valores de ICU permaneceram negativos, atingindo um pico de $-4,13^{\circ} \mathrm{C}$ no ponto 35 , o qual é caracterizado por um ambiente formado por uma LCZ 9.

Entre os pontos 7 e 9, pode-se observar o predomínio de áreas com a característica da ZCL 6, sendo que o relevo e a altura das edificações influenciaram a temperatura do ar a 60 metros de altura, que chegou a registrar $11,4^{\circ} \mathrm{C}$. 


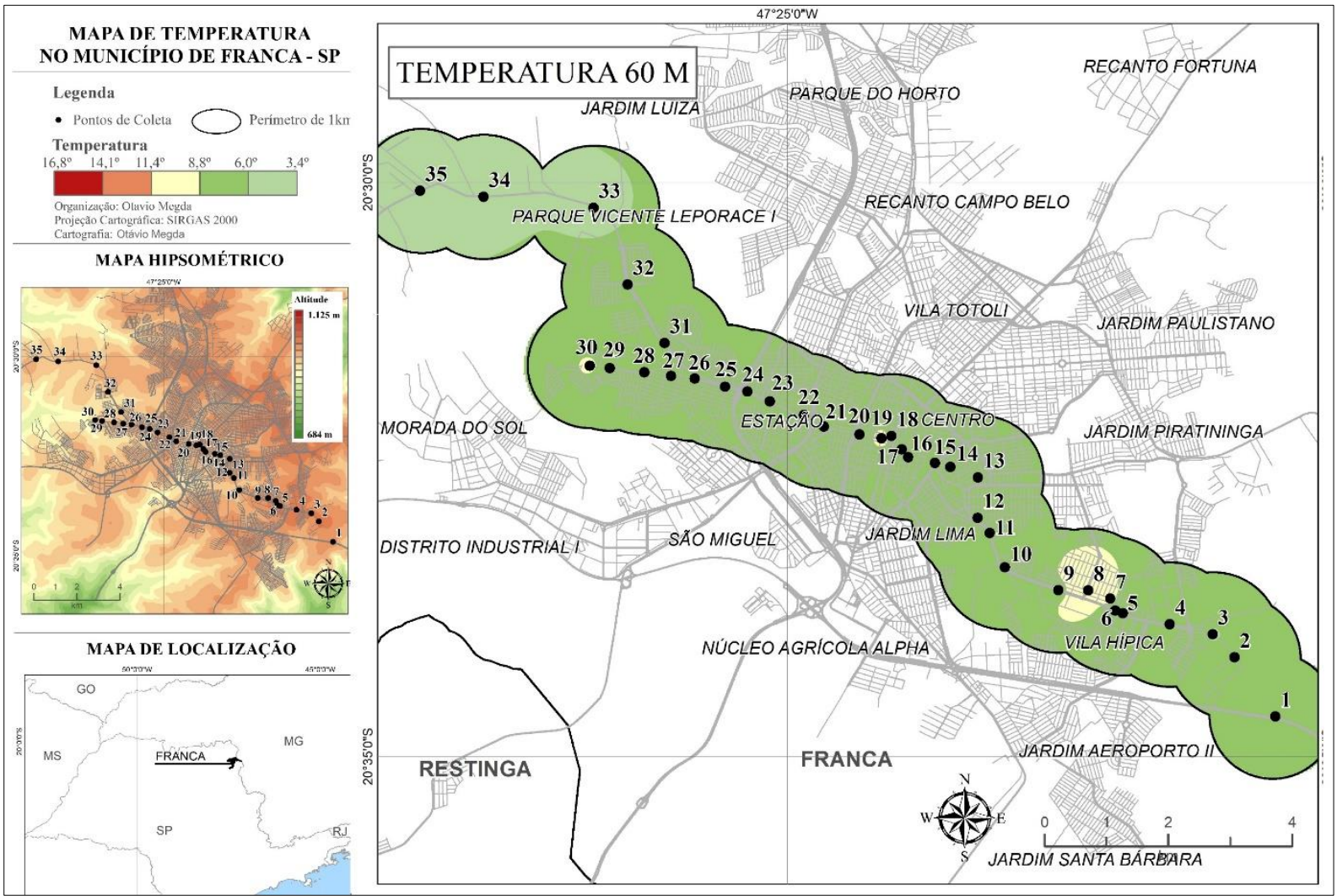

Figura 15 - Mapa com as temperaturas médias a 60 metros de altura em Franca - SP durante os dias de coleta em julho de 2018 com uso do VANT. Fonte: Elaborado pelo autor principal: Otávio Megda.

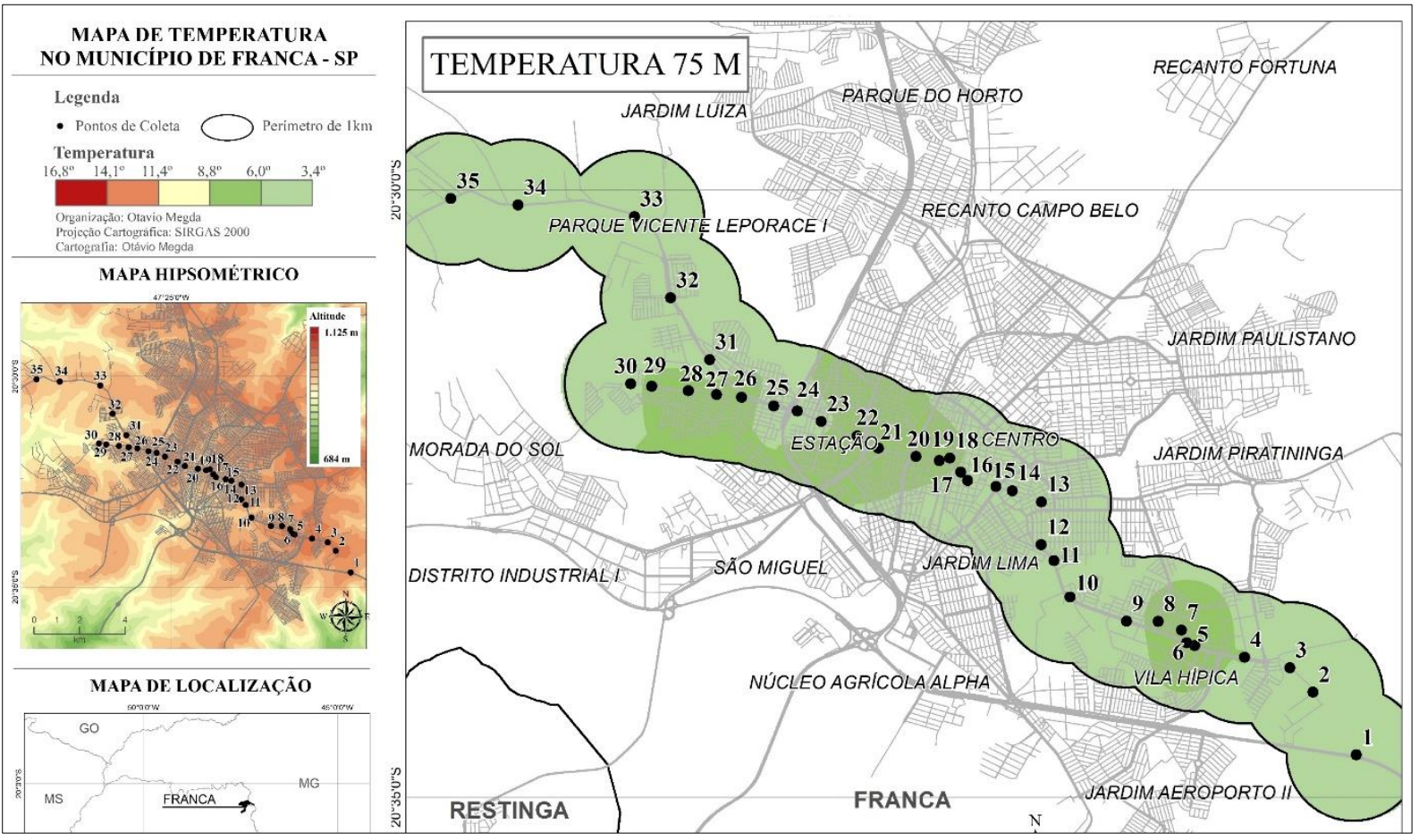

Figura 16 - Mapa com as temperaturas médias a 75 metros de altura em Franca - SP durante os dias de coleta em julho de 2018 com uso do VANT. Fonte: Elaborado pelo autor principal: Otávio Megda.

A figura 16 mostra a coleta das temperaturas absolutas do ar a 75 metros de altura, sendo que a variação de temperatura permaneceu entre $3,4^{\circ} \mathrm{C}$ e $8,8^{\circ} \mathrm{C}$ ao longo do percurso. As ICUs permaneceram com valores negativos, atingindo um pico de $-5,73^{\circ} \mathrm{C}$ também no ponto 35 , o qual é caracterizado por ser um ambiente rural. 
Segundo Brússolo \& Vecchia (2019), o tipo de ocupação do solo em áreas rurais, predominantemente mais vegetado, não tem a mesma capacidade de absorver e reter calor para superfícies urbanas mais impermeabilizadas. Portanto, a superfície das áreas rurais tende a perder calor mais rapidamente e o ar acima dela deixa de ser aquecido, possibilitando a entrada de ar frio próximo à superfície com uma camada de ar mais quente acima dela (Oke, 1978).

Entre as diversas técnicas de aquisição de informações micro meteorológicas, podemos destacar a distribuição de pontos fixos de medições, o transecto móvel ao nível do pedestre, o sensoriamento remoto e a obtenção de imagens de satélites. Cada técnica possui suas aplicações específicas, suas vantagens, desvantagens e limitações em escalas variáveis.

Entre as vantagens do uso de VANTs para estudos micro meteorológicos em escala urbana, destacamse a possibilidade de se observar em detalhes a real condição térmica do ar urbano em períodos curtos de tempo, sobretudo em cidades como Franca - SP, que apresenta grande variação de relevo e de configurações ambientais. Entretanto, é importante destacar a necessidade de se realizar o voo em dias com atmosfera estável para facilitar o posicionamento do VANT, o registro das informações com a precisão adequada dos dados, de acordo com Brússolo et al. (2018).

Brússolo (2015) relata ainda que o VANT deve dispor de bateria suficiente para se manter no ar até que os sensores termo-higrômetros se estabilizem e assim, registre medidas precisas. Equipamentos que disponham de no máximo 12 minutos de voo podem limitar a abrangência dos estudos de clima urbano, dependendo das características da cidade e do trajeto planejado.

Por outro lado, Ugeda (2011) estudou o clima urbano e o planejamento na cidade de Jales (SP) por meio de pontos fixos, transecto móvel e sensoriamento remoto e constatou que tais técnicas não foram suficientes para mostrar a atividade térmica ocorrida na CLU. Tsin et al. (2016) fizeram o monitoramento móvel da temperatura do ar em um percurso a pé em Vancouver, Canadá. Foram selecionadas 20 rotas com distintas áreas de acordo com as ZCLs propostas por Stewart e Oke (2012), comparando suas medições com as de 4 pontos fixos de monitoramento em diversas áreas da cidade para, finalmente, comparar estes com imagens do satélite LandSat. As discrepâncias se devem, possivelmente, ao fato de as repetições terem sido medidas em direções opostas e em lados opostos da rua, sob diferentes condições de ventos e sombreamento. Neste caso, a aplicação de um método que reconhecesse com mais precisão a forma urbana e o efeito térmico das superfícies urbanas na temperatura do ar instantaneamente talvez pudesse contribuir para uma discussão de informações mais consistente.

As análises obtidas por Souza et al. (2010) através da identificação das tendências térmicas em Bauru - SP, dados de máxima intensidade da ilha noturna em cada ponto, puderam oferecer base para a comparação com um modelo empírico, onde a pesquisa propôs uma equação de correção, e dados reais de pesquisas anteriores foram comparados com dados simulados pela nova equação, gerando resultados que indicaram que a temperatura urbana noturna varia de acordo com a faixa de fator de visão do céu considerada.

Liu et al. (2017) conduziram uma pesquisa em uma região com padrões urbanos diversificados na cidade de Shenzhen, China. A pesquisa recorreu ao transecto móvel com velocidade máxima de $20 \mathrm{~km} / \mathrm{h}$ no percurso. As coletas ocorreram em 24 pontos diferenciados em padrões durante 4 horários, em três dias consecutivos, sempre às $15 \mathrm{~h}$, e em 2 estações distintas do ano, em agosto de 2015 e janeiro de 2016. Esta pesquisa discutiu os padrões construtivos de cada área e sua influência para a melhoria da qualidade térmica do local. Entretanto, a carência de detalhamento das características sinóticas dos dias de coletas de dados e a consideração da área urbana apenas horizontalmente podem ter prejudicado a precisão dos registros das ICUs e sua abrangência espacial.

O trabalho de Assis et al. (2017) propõe a adaptação e aplicação da metodologia trabalhada por Katzschner (2005), desenvolvida por Scherer et al. (1999), na construção de mapas climáticos aplicando conceitos de climatopos para a cidade de Belo Horizonte - MG, com base em dados como uso do solo, aspectos geográficos e informações sobre os ventos, que foram analisados para a construção de diferentes 
camadas de mapas temáticos analisados, somando camadas e possibilitando a definição de oito classes de climatopos, criando um mapa climático mais analítico para a cidade.

A pesquisa realizada por Kotharkar \& Bagade (2018) teve como base a cidade de Nagpur, na Índia, levando em consideração as diferenças das ZCLs, utilizando-se de coleta de dados fixos e móveis. Os resultados mostraram que a intensidade de ICU dentro das ZCLs constituídas no inverno para a cidade de Nagpur varia de $1,76^{\circ} \mathrm{C}$ a $4,9^{\circ} \mathrm{C}$. Por fim, este estudo ainda analisou a variação térmica entre as ZCLs tradicionais e subclasses, possibilitando a identificação de ZCLs críticas em termos de ICU e sugerindo as devidas intervenções espaciais para se adequar às condições microclimáticas.

Ferreira \& Duarte (2019) pesquisaram a avaliação de parâmetros geométricos de desfiladeiros urbanos e como estes afetam seus microclimas e o conforto térmico de pedestres na cidade de Campinas - SP. 0 referido estudo utilizou a ferramenta computacional ENVI-met 4.0 preview, analisando um total de 36 cenários, com e sem espaço entre os edifícios, em duas estações do ano, com cenários que diferiram na proporção $(H / W)$ (avenida $(H / W<0,5)$, cânions regulares $(H / W=1,0)$ e profundos $(H / W>2,0)$ ) e comprimento para altura $(\mathrm{L} / \mathrm{H})$ razão (cânions curtos $[\mathrm{L} / \mathrm{H}<3,0]$, médios $[\mathrm{L} / \mathrm{H}=5,0]$ e longos $[\mathrm{L} / \mathrm{H}>7,0]$ ).

0 desempenho do cânion foi avaliado comparando a temperatura do ar, velocidade do vento e temperatura fisiológica equivalente (PET). Os resultados obtidos revelaram que desfiladeiros com maior relação $\mathrm{H} / \mathrm{W}$ aumentam a velocidade do vento e o sombreamento das edificações, melhorando o conforto térmico ao nível do pedestre, principalmente no verão. Por outro lado, um aumento na relação L/H não teve efeito significativo na sensação de conforto térmico ao nível do pedestre, que foi semelhante ao cenário sem espaçamento entre edifícios.

\section{Conclusão}

A utilização de VANTs na condução de pesquisas no campo térmico urbano abre muitas possibilidades de estudos. 0 espaço urbano, morada de mais de $90 \%$ dos brasileiros, dentre cidades pequenas, médias e grandes, é o palco de análise das relações atuais, podendo gerar estudos que ajudem a compreender as relações do homem com seu habitat, aprimorando a qualidade de vida.

É importante destacar que, ao ver as limitações da comprovação e análise das ICUs somente em dados terrestres e distribuídos de forma "horizontal", propôs-se analisar, numa nova metodologia proposta, a real interferência, sobretudo em escala vertical e na composição da Camada de Limite Urbano (CLU). Esta camada, sem interferência da ventilação natural tende a formar a composição da ICU.

Ainda, dentro desta perspectiva de análise, houve uma impossibilidade de comparação entre as medidas do VANT (nas três diferentes alturas) com os dados coletados pela estação automática do INMET, uma vez que essa é fixa e presa ao solo.

0 êxito na identificação das ICUs na área analisada em Franca foi possível com o uso de dois métodos conjuntos de coleta dos dados, horizontal a nível do pedestre, e outro vertical, com o VANT a 30, 60 e 75 metros de altura do solo, somados com parâmetros estabelecidos de uso e ocupação do solo, que garantiram análises mais precisas. Na verificação a nível de solo, por exemplo, o valor de $\mathrm{R}^{2}=0,2436$ entre a ocorrência de ICU e o FVC significa que o modelo linear explica $24,36 \%$ da variância da variável dependente incluída naquele modelo linear.

A relação entre a variação do FVC e a ocorrência de ICUs se mostrou consistente ao nível do pedestre, sendo que, quanto maior a altura, menor é a relação entre estas variáveis. Conclui-se, portanto, que o uso de VANTs para o registro de ocorrência e caracterização de ICU se mostra com elevado potencial, pois abre a possibilidade de se registrar fenômenos climáticos simultaneamente em trajetos horizontais e verticais em campanhas de coletas de informações de curto período, mas com grande capacidade de registro de informações. $\mathrm{O}$ fato de os VANTs serem ágeis, leves e possibilitarem deslocamento rápido e preciso, seu uso pode minimizar a interferência da radiação de onda longa sobre os sensores, o que melhora consequentemente a precisão dos dados coletados. 
A possibilidade de se verificar verticalmente a formação da ICU contribui para registrar comprometimento do ar citadino pela influência da ocupação urbana e, desta forma, auxiliar diversas pesquisas no cunho de planejamento e ordenamento territorial, bem como na gestão urbana de cidades com problemas relacionados ao campo do clima urbano.

\section{Referências}

Amorim, M. C. C. T. (2017). A interferência da precipitação na intensidade e na distribuição espacial das ilhas de calor de superfície nas estações do ano em ambiente tropical. In Anais do 18ํㅗ Simpósio Brasileiro de Sensoriamento Remoto (p. 13141320). Santos, SP.

Arnfield, A. J. (2003). Two decades of urban climate research: a review of turbulence, exchanges of energy and water, and urban heat island. International Journal of Climatology, 23, 1-26.

Assis, E. S., Ferreira, D. G., \& Katzschner, L. (2017). Construção de um mapa climático analítico para a cidade de Belo Horizonte, Brasil. Urbe, Rev. Bras. Gest. Urbana, 9(supl.1).

Bornstein, R. (1968). Observations of the Urban Heat Island Effect in New York. J. Appl. Meteor.

Brasil. Agência Nacional da Aviação Civil - ANAC (2017a). Orientações para usuário de drone. Recuperado em 02 de agosto de 2020 de http://www.anac.gov.br/assuntos/paginastematicas/drones/ orientacoes_para_usuarios.pdf

Brasil. Agência Nacional da Aviação Civil - ANAC (2017b). Regulamento Brasileiro da Aviação Civil Especial no 94/2017, de 02 mai. 2017. ANAC. Recuperado em 02 de agosto de 2020 de https://www.anac.gov.br/assuntos/legislacao/legislacao$1 /$ rbha-e-rbac/rbac/rbac-e-94

Brasil. Agência Nacional de Defesa Civil - ANAC (2017c). Resolução no 419/2017, de 02 de maio de 2017. Aprova o Regulamento Brasileiro da Aviação Civil Especial no 94. ANAC. Recuperado em 02 de agosto de 2020 de https://www.anac.gov.br/assuntos/paginas-tematicas/drones

Brasil. Casa Civil. Subchefia para Assuntos Jurídicos. (2009). Decreto nº 6.834, de 30 de abril de 2009. Aprova a Estrutura Regimental e o Quadro Demonstrativo dos Cargos em Comissão do Grupo-Direção e Assessoramento Superiores e das Funções Gratificadas do Comando da Aeronáutica, do Ministério da Defesa, e dá outras providências. Brasília: Casa Civil. Recuperado em 02 de agosto de 2020 de http://www.planalto.gov.br/ccivil_03/_Ato2007-

2010/2009/Decreto/D6834.htm

Brasil. Ministério da Defesa. Comando da Aeronáutica. Departamento de Controle de Espaço Aéreo - DECEA. (2015b). Portaria DECEA no 415, de 09 de novembro de 2015. Aprova a edição da ICA 100-40, que trata dos sistemas de Aeronaves Remotamente Pilotadas e o Acesso ao Espaço Aéreo Brasileiro. Ministério da Defesa, Comando da Aeronáutica, DECEA.

Brússolo, R. G., Pezzopane, J. R. M., \& Vecchia, F. A. (2018). Comparação termohigrométrica de sub-altitude em área urbana e rural em São Carlos, Brasil, por meio de VANT/DRONE. In Anais do $20^{\circ}$ Congresso Brasileiro de Meteorologia. Maceió: Universidade Federal de Alagoas.

Brússolo, R. G., \& Vecchia, F. A. (2019). Ub-altitude thermo-hyghrometric comparison in urban and rural area in highaltitude tropical climate by RPA/drone. Revista Brasileira de Climatologia, 25(15).

Brússolo, R. G. (2015). O clima e a cidade: Ilhas de calor em Assis (SP) (dissertação de mestrado). Universidade Estadual de Londrina, Londrina.

Debiazi, P. R. (2016). Mapeamento do ambiente térmico e suas relações com os parâmetros do entorno urbano (dissertação de mestrado). Universidade Federal de São Carlos (UFSCar), São Carlos, SP.

Fabbria, K., \& Costanzo, V. (2020). Drone-assisted infrared thermography for calibration of outdoor microclimate simulation models. Sustainable Cities and Society, 52. Recuperado em 17 de fevereiro de 2020 de https://www.sciencedirect.com/science/article/pii/S2210670719314738.

Ferreira, L. S., \& Duarte, D. H. S. (2019). Exploring the relationship between urban form, land surface Temperature and vegetation indices in a subtropical megacity. Urban Climate, 27, 105-123. https://doi.org/10.1016/j.uclim.2018.11.002

Franca, Prefeitura Municipal de. Secretaria da infraestrutura. Base cartográfica do município de Franca. Franca, 2014. Acessado dia 21/01/2018. 
Gaitani, N., Burud, I., Thiis, T., \& Santamouris, M. (2017). Aerial survey and in-situ measurements of materials and vegetation in the urban fabric. Procedia Engineering, 180, 1335-1344.

Galusic, B., \& Dornelles, K. A. (2017). Estudo da ilha de calor urbana em São Carlos/SP: como a permeabilidade dos revestimentos urbanos horizontais intervém nas variações da temperatura do ar. In Anais do $14^{\circ}$ Encontro Nacional \& $10^{\circ}$ Encontro Latino-Americano de Conforto no Ambiente Construído. Balneário Camboriú: Universidade do Vale do Itajaí. Recuperado em 18 de agosto de 2018 de https://repositorio.usp.br/item/002871825

Gartland, L. (2010). Ilhas de calor: como mitigar zonas de calor em áreas urbanas. Tradução Silvia Helen Gonçalves. São Paulo: Oficina de Textos.

Incoterm. (2018). Linha soluções em medição. Recuperado em 21 de janeiro de 2018 de https://www.incoterm.com.br/

Instituto Brasileiro de Geografia e Estatística - IBGE. (2010). Censo Demográfico 2010. Recuperado em 22 de agosto de 2018 de https://www.ibge.gov.br/cidades-e-estados/sp/franca.html

Instituto Nacional de Meteorologia - INMET. (2018). Banco de Dados Meteorológicos para Ensino e Pesquisa - BDMEP. Recuperado em 12 de agosto de 2018 de http://www. inmet.gov.br/projetos/rede/pesquisa/

Instituto Nacional de Pesquisas Espaciais - INPE. Centro de Previsão de Tempo e Estudos Climáticos - CPTEC. (2018a). Imagens de satélites meteorológicos. Recuperado em 12 de agosto de 2018 de http://satelite.cptec.ipe.br/home/

Instituto Nacional de Pesquisas Espaciais - INPE. Centro de Previsão de Tempo e Estudos Climáticos - CPTEC. (2018b). Boletim Técnico. Recuperado em 30 de julho de 2018 de http://tempo.cptec.inpe.br/boletimtecnico/pt

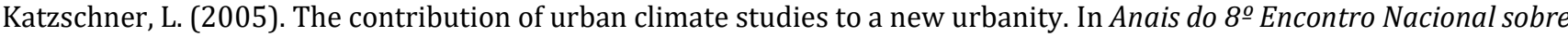
Conforto no Ambiente Construído (p. 912-920). Maceió: ENCAC, 2005.

Kotharkar, R., \& Bagade, A. (2018). Evaluating urban heat island in the critical local climate zones of an Indian city. Landscape and Urban Planning, 169, 92-104.

Kruger, E., \& Drach, P. (2017). Quantificação dos impactos da climatização artificial na sensação térmica de transeuntes em termos de alterações no microclima. Urbe. Revista Brasileira de Gestão Urbana, 9(suppl 1), 301-312.

Liu, L., Lin, Y., Liu, J., Wang, L., Wang, D., Shui, T., Chen, X., \& Wu, Q. (2017). Analysis of local-scale urban heat island. Characteristics using an integrated method of mobile measurement and GIS-based spatial interpolation. Bulding and Environment, 117, 191-207.

Masiero, E., \& Souza, L. C. L. (2018). Mapping humidity plume over local climate zones in a high-altitude tropical climate city, Brazil. Ambiente Construído, 18(4), 177-197.

Mendonça, R. S. R., \& Assis, E. S. (2003). Conforto Térmico Urbano: estudo de caso do bairro Floresta, Belo Horizonte. Ambiente Construído, 3(3), 45-63.

Mills, G. (2006). Progress toward sustainable settlements: A role for urban climatology. Theoretical Applied Climatology, (84), 69-76.

Muniz-Gäal, L. P., Pezzuto, C. C., Carvalho, M. F. H., \& Mota, L. T. M. (2020). Urban geometry and the microclimate of street canyons in tropical climate. Building and Environment., 169. https://doi.org/10.1016/j.buildenv.2019.106547

Naughton, J., \& McDonald, W. (2019). Evaluating the Variability of Urban Land Surface Temperatures Using Drone Observations. Remote Sensing, 11. Recuperado em 04 de janeiro de 2020 de https://www.mdpi.com/20724292/11/14/1722.2019.

Oke, T. R. (1976). The distinction between canopy and boundary layer urban heat islands. Atmosphere, 14(4), $268-277$.

Oke, T. R. (1978). Boundary layer climates. Methuen: Royal Meteorological Society.

Oke, T. R. (1982). The energetic basis of the urban heat island. Quarterly Journal of the Royal Meteorological Society, (108), $1-24$.

Oke, T. R., Mills, G., Christen, A., \& Voogt, J. (2017). Urban Climates. Cambridge: Cambridge University Press.

Scherer, D., Fehrenbach, U., Beha, H. D., \& Parlow, E. (1999). Improved concepts and methods in analysis and evaluation of the urban climate for optimizing urban planning processes. Atmospheric Environment, 33, 4185-4193.

Souza, L. C. L., Tente, C. M., Giunta, M. B., \& Nakata, C. M. (2010). Fator de visão do céu e intensidade das ilhas de calor na escala do pedestre. Ambiente Construído, 10(4), 155-167. 
Análise das llhas de Calor Urbano sobre Zonas Climáticas Locais com o uso de VANT

- Veículo Aéreo Não Tripulado - em uma cidade média

Stewart, I. D., \& Oke, T. R. (2012). Local climate zones for urban temperature studies. Bull. Am. Meteorol. Soc., 93(12), 1879-1900.

Tavares, C. P. (2020). Dinâmica climática e comportamento térmico em distintas Local Climate Zones em uma cidade tropical costeira (tese de doutorado). Programa de Pós-Graduação em Ciências Ambientais, Centro de Ciências Biológicas e da Saúde, Universidade Federal de São Carlos, São Carlos, SP.

Tsin, P. K., Knudby, A., Krayenhoff, E. S., Ho, H. C., Brauer, M., \& Henderson, S. B. (2016). Microscale mobile monitoring of urban air temperature. Urban Climate, 18, 58-72.

Ugeda, J. C. (2011). Clima e Planejamento na cidade de Jales-SP (tese de doutorado). Faculdade de Ciências e Tecnologia, Universidade Estadual Paulista, Presidente Prudente, SP.

Editor responsável: Paulo Nascimento Neto

Recebido: 11 set. 2020

Aprovado: 26 ago. 2021 